\title{
Modelling design of wind turbine generator
}

\author{
Thaker Nayl ${ }^{1,3}$, Mohammed Q. Mohammed ${ }^{2,3}$ and Saif Q. Muhamed $^{3}$ \\ Luleå University of Technology, Sweden ${ }^{1}$ \\ Al-Esraa University college, Iraq ${ }^{2}$ \\ University of information Technology and communications, $\mathrm{Iraq}^{3}$
}

Received: 31-August-2021; Revised: 16-January-2022; Accepted: 18-January-2022

(C)2022 Thaker Nayl et al. This is an open access article distributed under the Creative Commons Attribution (CC BY) License, which permits unrestricted use, distribution, and reproduction in any medium, provided the original work is properly cited.

\begin{abstract}
The development of control systems to improve efficiency requires accurate mathematical models. This article deals with the modelling of two-mass variable speed wind turbine generators. A model design of a $3.5 \mathrm{MW}$ vertically axial wind generator and a mathematical model of an electromechanical system is considered in this article. Wind turbine generators behave to have the most significant uncertainty, specified the possibility for nonlinear behaviour. The main focus is on structural aerodynamics, including the forcing and motion of the rotating parts of the turbine. The turbine's critical structural aerodynamics and mechanical components are the blade pitch actuators, drive shaft actuators, and turbine specifications. With an accurate wind turbine model, the control engineers will design control systems to reduce loads, increase the operating lifetime, and increase electrical power. Methods of linearization about operating points have been proposed to enable an efficient control system design. The results show that the model can be used in different strategies evaluation.
\end{abstract}

\section{Keywords}

Wind turbine model, Linearization strategies, Blade pitch angle, Mechanical torque.

\section{Introduction}

The wind turbine generator is a complex model system due to its nonlinear aerodynamics structure. More accurate models resolve more physical processes, but it's challenging to obtain a precise system model. It is, therefore, imperative to build a suitable system model for design controllers to optimize energy and reduce loads. However, the advanced aerodynamics models tend to be computationally consuming and therefore be complex for control system design and stability analysis. The nonlinearity and the fluctuations of wind speed give rise to many challenges in the design and control of wind turbines. To enable an efficient control system to design we need to build mathematical wind turbine model. Therefore, it is necessary to investigate the modelling in a systematic and integrated manner from the viewpoints of validity and computational cost, which has not yet been completely addressed. The complexity of the design model is determined based on a compromise, as a high level of complexity can lead to a highly complex control design.

\footnotetext{
*Author for correspondence
} 
The aerodynamic modelling of the wind turbine has been studied and presented in several research papers as [1], and it can be estimating the aerodynamic coefficient power by an artificial neural network [2]. A complete modelling and control technique of variable speed wind turbine system proposed in [3].

Over the past years, various techniques for modelling wind turbines have been developed in many aspects in the scientific articles in [4-8]. The basic concepts of the mathematical modelling of the wind generators and its state-space linearization methods have been presented. Numerous linear and nonlinear control methods have been designed based on the accuracy of the turbine model $[9,10]$. A method to construct reduced-order models nonlinear and developed analytical wind turbine systems as described in [11].

The design horizontal wind turbine variable speed model consists of an aerodynamic model, a pitch actuator, a generator model, and a model for the driveshaft. The organization of this article is as follows. Section 2 demonstrate the literature review of the turbine model. Section 3 illustrate the methods to understand the physical mechanisms model. In Section 4 demonstrating the simulation results. Section 5 discussing the simulation results. Finally in section 6 conclusion and future work, includes the outcomes of the article.

\section{Literature review}

The turbine's kinetic energy obtained by the wind blades is transformed into mechanical torque at the rotor shaft of the wind turbine [12]. The model is described as in the Figure 1. Some of the controller criteria differ depending on the wind speed region and the design model. The most mode control in a wind turbine is the blade pitch angle and the torque delivered from the generator. The blade pitch control is achieved with collective motion control.

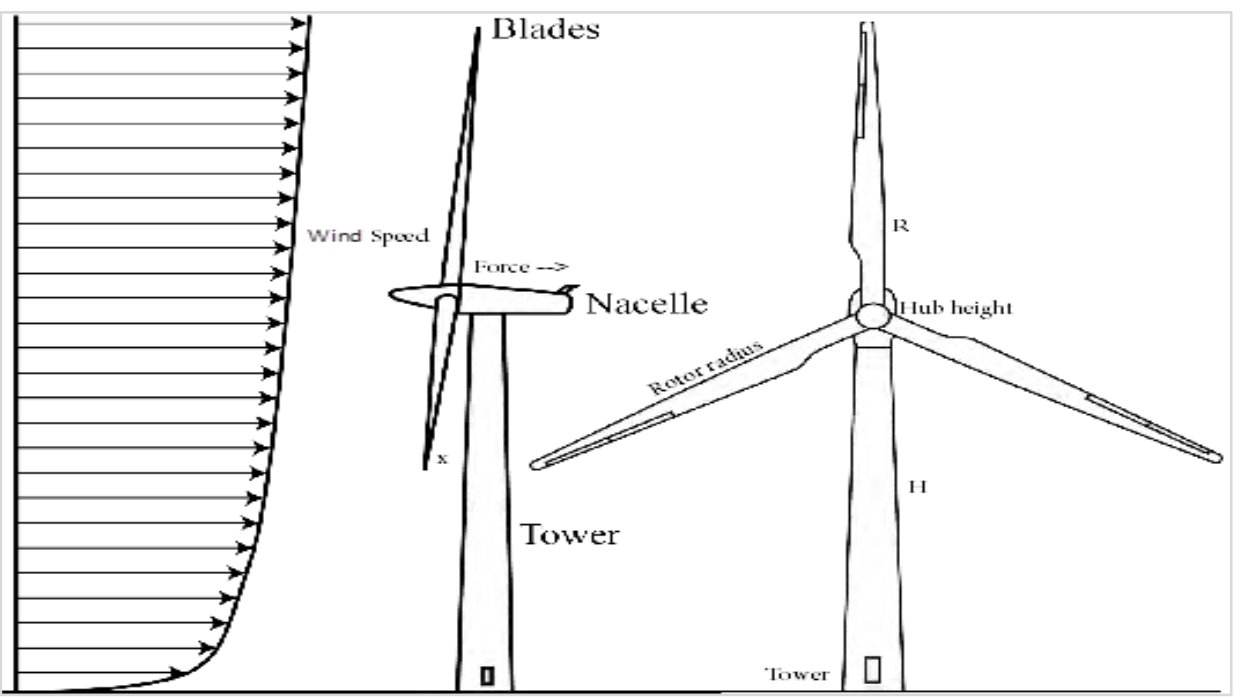

Figure1Horizontal wind turbine generator

Therefore, there are different control strategies selected based on which region the wind turbine operates. The article aims to present an overview of the identical modelling of wind turbines.

A comprehensive review of wind turbine generator modelling for increasing the operating lifetime and increasing electrical power will be presented. Models of wind turbine generators using machine learning have been reviewed in [13]. A review of modelling of wind turbine generators considering the aspects of time scale and stability methodology has been presented in [14]. A mathematical model of wind turbine based on induction generator has been developed in [15]. A simulated system of modelling of wind turbine using differential equations has been simulated in [16]. The overall analysis of modelling and control design for variable speed wind turbine systems has been presented in [17]. A combination of the wind turbine models based on their strength in predicting desirable factors in the operating regions have been suggested in [18]. A wind turbine model using an artificial neural network to predict power generation has been proposed in [19]. An electromechanical system modelling has been proposed to be extracting the maximum efficiency of 
wind turbines in [20]. These models have been contingent on aerodynamic models, which are only valid for no disturbances of tower bending and torsion of mode shapes deviations around an axis tower, such that they are restricted to ideal operating conditions. Therefore, the aim of this article is to build mathematical wind turbine linear and nonlinear models for control design and compare their performance regarding the disturbances of tower bending and torsion of mode shapes.

\section{Methods}

According to the wind speed range, the wind turbine has three operation regions denoted the low, mid, and high regions, as shown in Figure 2. The low region (Region I) starts when the rotor speed reaches the rated value to capture the maximum power [21]. The mid-region (Region II) starts at the rated wind speed, the rotor speed can reach its rated value, and the nominal power is achieved. In the high region (Region II), the wind speed is above the rated value and below the peak region [22]. The peak region (Region IV) starts at a speed value above $(25 \mathrm{~m} / \mathrm{s})$; the turbine must stop in this region.

The simplest way to model a wind turbine is with a first order system. Here, only dynamics in the rotational speed are considered, which is determined by the theoretically possible energy in the wind and the aerodynamic efficiency of the turbine.

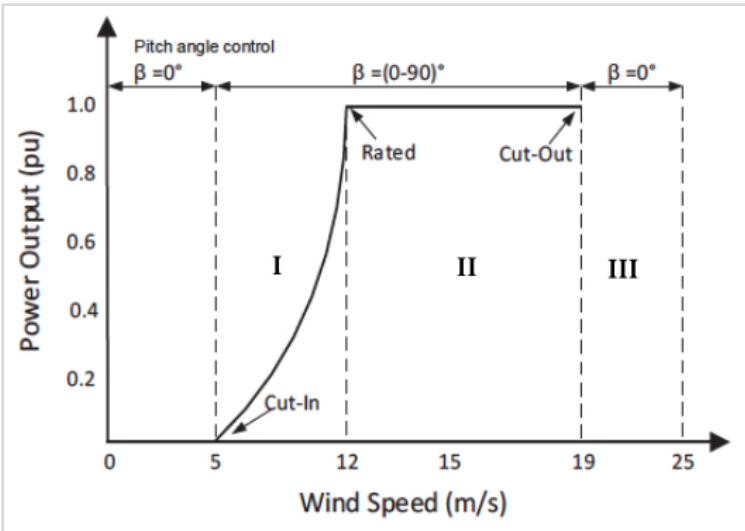

Figure 2 Wind speed regions

\subsection{Aerodynamic and mechanical model}

The complete working mechanism of wind turbine model is shown in Figure 3. where ( $\mathrm{x}$ ) is the state vector of the turbine model. The main subsystems are the aerodynamic, the mechanical (drive train and tower structure), the pitch actuator and generator subsystem (converter), as summarized in the Figure 3.

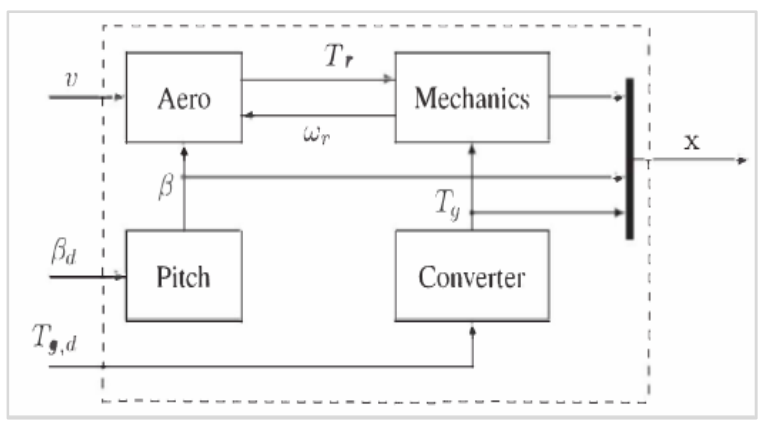

Figure 3 The complete working mechanism of wind turbine generator model

The verity of the rotor angular speed $\left(w_{r},[\mathrm{rad} / \mathrm{sec}]\right)$ is generated from the differences of the aerodynamic torques, as follow (Equation 1).

$J_{t} \dot{w}_{r}=T_{r}-T_{g} N_{g}$

Where $\left(J_{t},\left[\mathrm{kgm}^{2}\right]\right)$ is the total inertia of moment, $\left(T_{g},[\mathrm{Nm}]\right)$ is the generator torque, $\left(N_{g}\right)$ is the ratio speed and $\left(T_{r} ;[\mathrm{Nm}]\right)$ is the rotor torque, which can express as (Equation 2).

$T_{r}=\frac{P_{r}}{w_{r}}$

Since the power $\left(P_{r}\right)$ can now be calculated, it is possible to find the last stationary value $\left(T_{g}\right)$ from the Equation 3.

$T_{g}=\frac{P_{r}}{w_{r} N_{g}}$

where $\left(P_{r}\right.$, [watt]) is the powerful effect of the wind hitting the rotor area. The total inertia of moment $\left(J_{t}\right.$; $\left.\left[\mathrm{kgm}^{2}\right]\right)$ can be calculated by using the Equation 4 . $J_{t}=J_{r}+J_{g} N_{g}^{2}$

The high-speed shaft angle rate of the turbine generator can be expressed as follows (Equation 5).

$w_{g}=N_{g} w_{r}$

A value must now be determined that gives the desired output power $\left(P_{g}\right)$ (Equation 6).

$P_{g}=T_{g} w_{g}$

The aerodynamic efficiency of the wind turbine is indicated by an efficiency parameter called the $\left(C_{p}\right)$ curve. Rotor power $\left(P_{r}\right)$ represents the aerodynamic torque $\left(T_{r}\right)$ multiplied by the rotational speed of the rotor $\left(w_{r}\right)$ (Equation 7$)$. 
$P_{r}=T_{r} w_{r}$

The $\left(C_{p}\right)$ curve depends on the pitch of the blades $(\beta)$ as well as the ratio between the equivalent wind speed $\mathrm{v}$ and the tipping speed of the blades called the tip speed ratio $\left(\lambda,\left[\mathrm{rad}^{-1}\right]\right)$. The electrical power $\left(P_{e}\right)$ is due to some losses in the wind turbine (Equation 8).

$P_{e}=\eta P_{r}$

where, $(\eta)$ is the efficiency of the electrical power generation. The power wind turbine $\left(P_{w}\right)$ is directly proportional to the cube of the wind speed, which can be formulated below (Equation 9).

$P_{w}=0.5 A \rho v^{3}$

where the rotor area $\left(A=\pi R^{2},\left[m^{2}\right]\right),(R,[m])$ is the rotor turbine radius and $\left(\lambda=\frac{v}{R w_{r}}\right)$ is the tip speed ratio formula.

The rotor power $\left(P_{r}\right)$ can be extracted from the wind power as follows (Equation 10).

$P_{r}=P_{w} C_{p}=0.5 A \rho v^{3} C_{p}$

(10)
The aerodynamic performance is the ratio of instant turbine power to wind power, defined as follows (Equation 11).

$C_{p}=0.5176\left(116 \lambda_{i}-0.4 \beta-5\right) e^{-21 \lambda_{i}}$

The coefficient $\left(\lambda_{i}\right)$ can calculate using the following formula (Equation 12).

$\lambda_{i}=\frac{1}{\lambda+0.08 \beta}-\frac{0.035}{1+\beta^{3}}$

Based on the above equations (1-12), it is now possible to set up the differential Equation 13, that describes a simple wind turbine model.

$\dot{w}_{r}=\frac{P_{r}}{J_{t} w_{r}}-\frac{T_{g} N_{g}}{J_{t}}$

The optimum region map of power against pitch angle and tip speed ratio is shown in Figure 4. A unique optimal value of tip speed ratio $\lambda$ can satisfy maximum power coefficient $C_{p}$ under controlling blades pitch angle $\beta$.

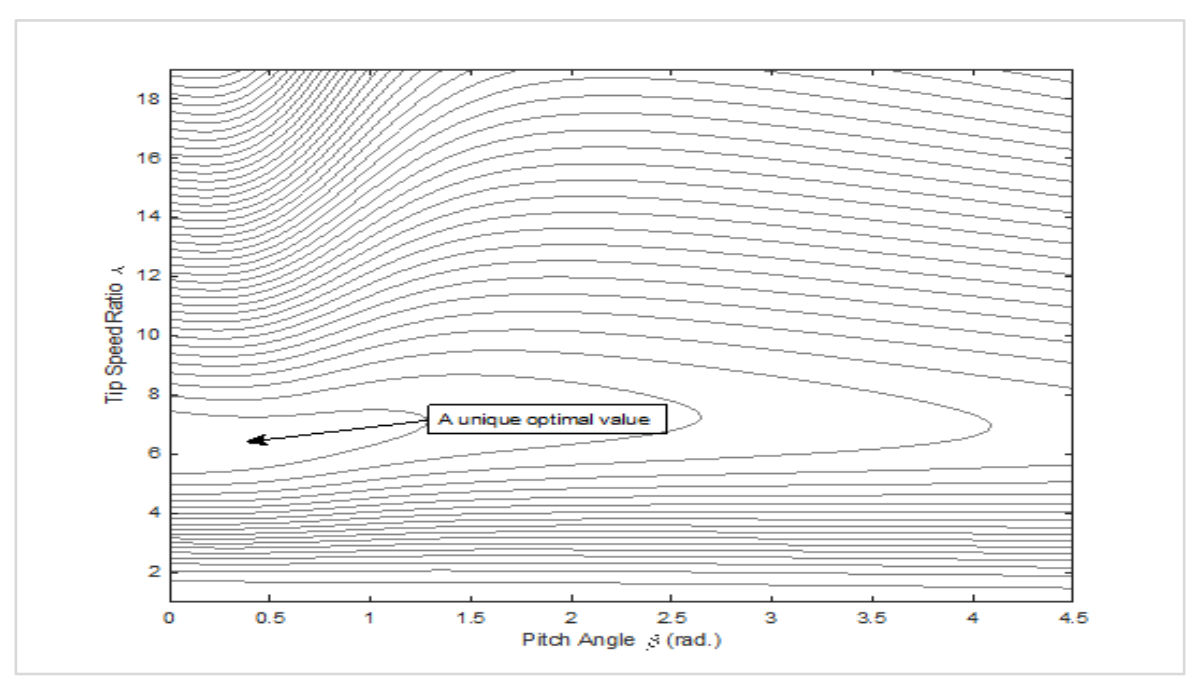

Figure 4 Power coefficient curves vs tip-speed ratio and the blades pitch angle

During the description of the aerodynamic model, it is seen that this part is a non-linear system. It is, therefore, necessary to linearize the wind turbine system at a given wind speed before a sensible controller can be designed. The linearized system in a state-space model over the system, shown below (Equation 14 and 15)..

$\dot{\bar{x}}=A_{a} \bar{x}+B_{a} \bar{u}$

$\bar{y}=C_{a} \bar{x}+D_{a} \bar{u}$ where the $(\bar{x}, \bar{u}, \bar{y})$ are the state, the input, and the output vectors respectively. Which is can be defined as follows (Equation 16).

$\bar{x}=\left[w_{e}\right], \quad \bar{x}=\left[\begin{array}{c}v \\ \beta \\ T_{g}\end{array}\right], \quad \bar{y}=\left[\begin{array}{c}w_{r} \\ w_{g} \\ P\end{array}\right]$

where $\left(w_{g},[\mathrm{rad} / \mathrm{s}]\right)$ is the angular velocity of generator and $(\mathrm{P},[w a t t])$ is the supply electric power. The train dynamics of the rotor angular speed can be written as follows (Equation 17). 
Thaker Nayl et al.

$\dot{W}_{r}=\frac{0.5 A \rho v^{3} C_{p}}{J_{t} w_{r}}-\frac{T_{g} N_{g}}{J_{t}}$

According to the aerodynamic model, the non-linear function of rotor speed, wind speed, pitch angle and generator torque can be formulated into linear at $\left[w_{\text {rop }}\right]$, and the function can be as below (Equation 18).

$A_{a}=\left[\frac{\partial \dot{w}_{r}}{\partial w_{r}}\right]$

The linearization of the aerodynamic can calculated by assuming that the $\left(T_{r} \approx T_{g} N_{g}\right)$ at the operating points (Equation 19).

$\left[v_{o p}, \beta_{o p}, T_{g o p}\right]$.

$B_{a}=\left[\begin{array}{lll}\frac{\partial \dot{w}_{r}}{\partial v} & \frac{\partial \dot{w}_{r}}{\partial \beta} & \frac{\partial \dot{w}_{r}}{\partial T_{g}}\end{array}\right]$

The output vector is (Equation 20).

$C_{a}=\left[\begin{array}{c}1 \\ N_{g} \\ T_{g} N_{g}\end{array}\right]$

The value of $D_{a}=0$ and the value of $A_{a}$ can be expressed as (Equation 21).

$A_{a}=\frac{\partial}{\partial w_{r}}\left[\frac{0.5 A \rho v^{3} C_{p}}{J_{t} w_{r}}-\frac{T_{g} N_{g}}{J_{t}}\right]$

Also, can get (Equation 22),

$A_{a}=\left[\left[\frac{0.5 A \rho v^{3}}{J_{t} w_{r}} \frac{\partial c_{p}}{\partial w_{r}}-\frac{0.5 A \rho v^{3} C_{p}}{J_{t} w_{r}^{2}}\right]\right]$

The differential expression is still included in determining the coefficient analytically, $\frac{\partial c_{p}}{\partial w_{r}}$ which is not possible. Therefore, it's necessary to find the coefficient numerically. Also, it is not possible to find the differentiation concerning $w_{r}$. Noted that the $C_{p}$ curve is a function of $\lambda$ and $\beta$. Then, a new expression can write it as below (Equation 23).

$\frac{\partial C_{p}}{\partial w_{r}}=\frac{\partial C_{p}}{\partial \lambda} \frac{\partial \lambda}{\partial w_{r}}$

For $\frac{\partial \lambda}{\partial w_{r}}$ can calculated by using the formula $(\lambda=$ $\left.\frac{v}{R w_{r}}\right)$.

The final expression of Aa matrix can be determined in the below Equation 24.

$A_{a}=\left[-\left[\frac{0.5 A \rho v^{3}}{J_{t} w_{r}}\left(\frac{v}{R w_{r}^{2}}\right) \frac{\partial C_{p}}{\partial \lambda}+\frac{0.5 A \rho v^{3} C_{p}}{J_{t} w_{r}^{2}}\right]\right]$ where $\frac{\partial \lambda}{\partial w_{r}}$ can find it numerically.

Same procedure is now used to find the $B_{a}$ matrix (Equation 25).

$B_{a}=\left[\begin{array}{c}\frac{1.5 A \rho v^{2} C_{p}}{J_{t} w_{r}}+\frac{0.5 A \rho v^{3} C_{p}}{J_{t} R w_{r}^{2}} \frac{\partial C_{p}}{\partial \lambda} \\ \frac{0.5 A \rho v^{3}}{J_{t} w_{r}} \frac{\partial C_{p}}{\partial \beta} \\ \frac{-N_{g}}{J_{t}}\end{array}\right]^{T}$

To differentiate the $\mathrm{Cp}$ curve concerning the wind, we can use the same techniques as above. The simple linearization wind turbine model has been set up around a suitable linearization point. Since the wind turbine can operate in three different regions (low, mid, and high), it is necessary to calculate the suitable stationary values in three different ways. In high wind speed, the turbine angular velocity can exceed design limits, and then the turbine should not be operated without a load. The standard operating region of the wind turbine will be rotating at fixed rotational velocity.

\subsection{Pitch actuator model}

A hydraulic servo system controls the pitch of the wind turbine. The dynamics of the actuator are therefore only described as a linear model.

The model is shown in the following state-space Equations 26 and 27.

$\dot{\bar{x}}=A_{\beta} \bar{x}+B_{\beta} \bar{u}$

$\bar{y}=C_{\beta} \bar{x}$

where the $(\bar{x}, \bar{u}, \bar{y})$ are the state vector, the input vector, and the output vectors respectively. A mechanical hydraulic actuator changes the control of pitch angle, expressed as follows (Equation 28).

$\dot{\beta}=\frac{1}{\tau_{\beta}} \beta+\frac{1}{\tau_{\beta}} \beta_{d}$

where $\beta_{d}$ is the desired pitch blade angle and $\tau_{\beta}$ is the time constant of the pitch actuators. Which can be written in the state-space Equation 29 and 30 as follows.

$\bar{x}=[\hat{\beta}], \quad \bar{u}=\left[\beta_{d}\right], \quad \bar{y}=[\beta]$

$A_{\beta}=\left[-\frac{1}{\tau_{\beta}}\right], \quad B_{\beta}=[1], \quad C_{\beta}=\left[\frac{1}{\tau_{\beta}}\right]$

Control the blade pitch angle to maintain the desired operating condition. 


\subsection{Generator model}

The wind turbine generator model is used, which can supply the desired torque, with which it is possible to regulate the wind turbine's rotational speed and power output. It is seen that such a generator can be modelled satisfactorily with a simple system, as follows [23] (Equation 31).

$\dot{T}_{g}=\frac{1}{\tau_{g}}\left(T_{g d}-T_{g}\right)$

where $T_{g d}$ is the desired generator torque and $\left(\tau_{g},[\mathrm{~s}]\right)$ is the time constant of the generator. As the desired generator torque which is given by the relation $T_{g d}=\frac{P_{g d}}{w_{g}}$, can get the following relation (Equation 32).

$\dot{T}_{g}=\frac{1}{\tau_{g}}\left(\frac{P g d}{w_{g}}-T_{g}\right)$

where $P_{g d}$ is the desired output electrical power. By using Laplace transformation and a bit of relocation, can get (Equation 33).

$\frac{T_{g}}{T_{g d}}=\frac{1}{\tau_{g}+1}$

where the again taken from the double model $\left(\tau_{g}=\right.$ $0.1 \mathrm{~s}$ ), this provides bandwidth for the actuator. The system in the linear state-space model can be set up directly based on the transfer function, shown in the following form (Equation 34 and 35).

$\bar{x}=\left[\widehat{T}_{g}\right], \quad \bar{u}=\left[T_{g d}\right], \quad \bar{y}=\left[T_{g}\right]$

$A_{g}=\left[-\frac{1}{\tau_{g}}\right], \quad B_{g}=[1], \quad C_{g}=\left[\frac{1}{\tau_{g}}\right]$

The output of the generator model is the torque at a high speed of $T_{g}$.

\subsection{Drive shaft actuator model}

The rotating part in the hub consists of the blades, the axis that connects the blades to the overdrive system and the pitch angle servos, which rotate the blades around their longitudinal axes. The transmission system consists of low and high-speed shafts, gearboxes, and brakes. The drive shaft model that drives the gearbox and generator is not entirely rigid. The driveshaft is modelled as a spring with damping and a mass at each end. The dynamics of the drive shaft and the structural part of the simplified wind turbine have here been put together into a single system, depicted in Figure 5. It is noted that only the drive shaft on the rotor side is considered elastic and that the gear is lossless.

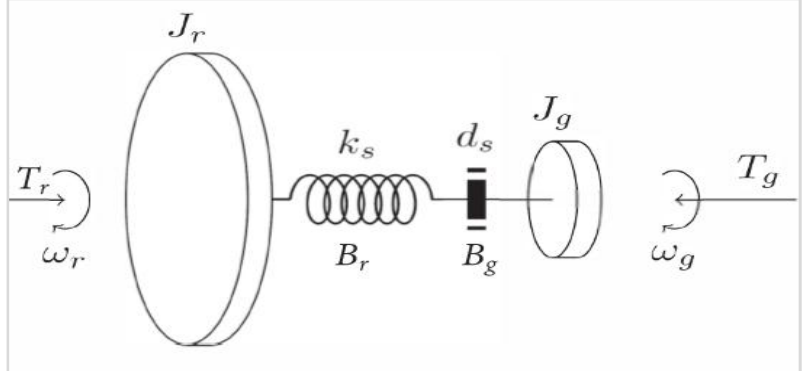

Figure 5 Drive shaft model

As depicted in Figure 6, the dynamic of the shafttorque can be described by the following Equation 36 and 37.

$T_{g}=k_{s} \theta+d_{s} \dot{\theta}$

$\dot{\theta}=\dot{\theta}_{r}-\frac{\dot{\theta}_{g}}{N_{g}}=w_{r}-\frac{w_{g}}{N_{g}}$

The drive train dynamics, which describes the system using $\dot{w}_{r}=\ddot{\theta}_{r}$ can now be seen below (Equation 38).

$\dot{w}_{r}=\frac{1}{J_{r}}\left(T_{r}-d_{s} w_{r}+\frac{d_{s} w_{g}}{N_{g}}-k_{s} \int\left(w_{r}-\frac{w_{g}}{N_{g}}\right) d t\right)$

The same procedure was also used to find the $\dot{w}_{g}$. The constants are defined as the drive train damping factor $\left(d_{s}=10^{7} 1 / \mathrm{s}\right)$ as well as the drive train spring factor $\left(k_{s}=5.6^{*} 10^{9} \mathrm{~N} / \mathrm{m}\right)$.

The constants $\left[d_{s}, k_{s}\right]$ are determined from the resonant frequency $w_{s}=2 \pi f_{s}$ of the shaft from below relation (Equation 39 and 40).

$k_{s}=J_{r} w_{s}^{2}$

$d_{s}=0.01 k_{s}$

Here it should be noted that and $T_{g}=J_{g} \dot{w}_{g}, T_{r}=$ $J_{r} \dot{w}_{r}$ and $\dot{\theta}=w_{r}-\frac{w_{g}}{N_{g}}$.

The Equations (36, 37 and 38) can therefore be reduced as shown below (Equation 41-46).

$\dot{w}_{r}=-\frac{\left(B_{r}+d_{s}\right)}{J_{r}} w_{r}+\frac{\left(d_{s} w_{g}\right)}{J_{r} N_{g}}-\frac{\left(k_{s} \theta\right)}{J_{r}}+\frac{T_{r}}{J_{r}}$

$\dot{w}_{g}=-\frac{d_{s}}{J_{r} N_{g}} w_{r}-\left(\frac{d_{s}}{J_{g} N_{g}^{2}}+\frac{B g}{J_{g}}\right) w_{g}-\frac{\left(k_{s} \theta\right)}{J_{r} N_{g}}+\frac{T_{g}}{J_{g}}$

$\dot{\theta}=w_{r}-\frac{1}{N_{g}} w_{g}$

It can now be set up in a state-space model, which is seen as follow. 


$$
\begin{aligned}
& \bar{x}=\left[\begin{array}{c}
w_{r} \\
w_{g} \\
\theta
\end{array}\right], \bar{u}=\left[\begin{array}{l}
T_{r} \\
T_{g}
\end{array}\right], \quad \bar{y}=\left[\begin{array}{c}
w_{r} \\
w_{g} \\
P \\
\theta
\end{array}\right] \\
& A_{D}=\left[\begin{array}{ccc}
-\frac{\left(B_{r}+d_{s}\right)}{J_{r}} & \frac{d_{s}}{J_{r} N_{g}} & \frac{k_{s}}{J_{r}} \\
-\frac{d_{s}}{J_{r} N_{g}} & -\frac{d_{s}}{J_{g} N_{g}^{2}}-\frac{B_{g}}{J_{g}} & -\frac{k_{S}}{J_{r} N_{g}} \\
1 & -\frac{1}{N_{g}} & 0
\end{array}\right] \\
& B_{D}=\left[\begin{array}{cc}
\frac{1}{J_{r}} & 0 \\
0 & -\frac{1}{J_{r}} \\
0 & 0
\end{array}\right], C_{D}=\left[\begin{array}{ccc}
1 & 0 & 0 \\
0 & 1 & 0 \\
0 & T_{g} & 0 \\
0 & 0 & 1
\end{array}\right]
\end{aligned}
$$

All parts of the design model have now been described. An overall state-space model is currently being created for the design model.

\subsection{Mechanical system model}

The simple wind turbine model is helpful in the corresponding analysis of different control strategies, whereas the dynamic factors can treat as uncertainties. This model has two degrees, particularly the torsion of the drivetrain and the axial tower bending. The existence of these fundamentals requires careful design of the wind turbine and control unit [24]. The wind turbine model included the first mode of the drivetrain and the tower bending. Figure 6 shows a schematic diagram of the mechanical model.

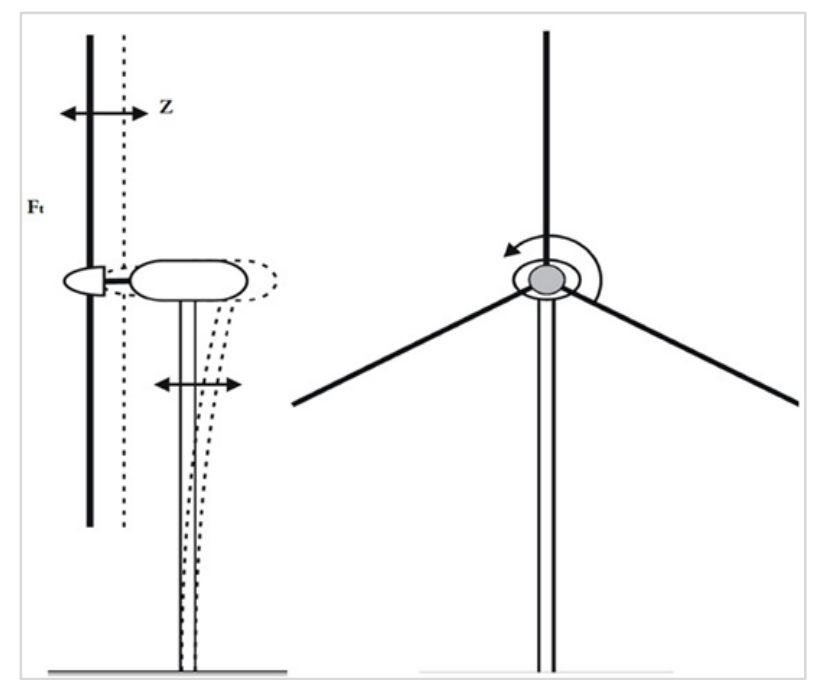

Figure 6 Tower bending and torsion of mode shapes

The incoming wind velocity $v$ is superimposed by the nacelle velocity $\dot{z}$ resulting from the deflection of the wind from the tower by the Equation 47.

$v_{r}=v-\dot{z}$
The additional term $\dot{z}$ is the axial shift of the blades due to the bending of the tower, which can be expressed as follows (Equation 48).

$m_{t} \ddot{z}=-K_{t} z-D_{t} \dot{z}+F_{t}$

where $m_{t}$ is the mass of the turbine tower and nacelle, $K_{t}$ is the tower's stiffness, $D_{t}$ is the damping of the turbine tower. The aerodynamic thrust Ft is given by the following Equation 49 .

$F_{t}=0.5 A \rho v_{r}^{2} C_{T}(\lambda, \beta)$

where the thrust coefficient $C_{T}$ is a function of tip speed ratio $\lambda$ and the blade pitch angle $\beta$. Defining the state space as follows (Equation 50).

$\left[\begin{array}{l}\dot{Z} \\ \ddot{z}\end{array}\right]=\left[\begin{array}{cc}0 & 1 \\ \frac{-K_{t}}{m_{t}} & \frac{-D_{t}}{m_{t}}\end{array}\right]\left[\begin{array}{l}Z \\ \dot{z}\end{array}\right]+\left[\begin{array}{c}0 \\ \frac{F_{t}}{m_{t}}\end{array}\right]$

where $z, \dot{z}$ and $\ddot{z}$ represents the position, velocity, and acceleration of the nacelle of the tower, respectively. The parameters are selected as following, $m_{t}=250 * 10^{3} \mathrm{Kg}, k_{t}=8.88 * 10^{5} \mathrm{Nm}$ and $D_{t}=296 * 10^{2} \mathrm{Ns} / \mathrm{m}$.

\subsection{Overall state space model}

Overall design models are used of increasing complexity, and it is an advantage to make the aggregation of the turbine model in one step. The model is now being expanded with the generator model, and the two actuators, pitch angle actuator and driveshaft actuator, are described as follows.

$\dot{\bar{x}}=A_{e q} \bar{x}+B_{e q} \bar{u}$

$\bar{y}=C_{e q} \bar{x}$

These Equations 51 and 52 can be written by defining new state, input, and output vectors, as follow (Equation 53).

$$
\bar{x}=\left[\begin{array}{c}
\hat{\beta} \\
\widehat{T}_{g} \\
w_{r} \\
w_{g} \\
\theta \\
z \\
\dot{z}
\end{array}\right], \bar{u}=\left[\begin{array}{c}
v_{r} \\
\beta_{d} \\
P_{g d}
\end{array}\right], \bar{y}=\left[\begin{array}{c}
w_{r} \\
w_{g} \\
P_{r} \\
\theta
\end{array}\right]
$$

The below equations are describing the complete stats $\dot{\bar{x}}$ of the system (Equation 54-59).

$$
\begin{aligned}
& \hat{\dot{\beta}}=\frac{1}{\tau_{\beta}} \hat{\beta}+\frac{1}{\tau_{\beta}} \beta_{d} \\
& \hat{\dot{T}}_{g}=\frac{1}{\tau_{g}}\left(\frac{P g d}{w_{g}}-\widehat{T}_{g}\right) \\
& \widehat{\hat{w}}_{r}=\frac{0.5 A \rho v_{r}^{3} c_{p}}{J_{r} w_{r}}-\frac{\left(d_{S}\right)}{J_{r}} w_{r}+\frac{\left(d_{s} w_{g}\right)}{J_{r} N_{g}}-\frac{\left(k_{s} \theta\right)}{J_{r}}
\end{aligned}
$$


$\widehat{\hat{w}}_{g}=-\frac{\widehat{T}_{g}}{J_{g} \tau_{g}}+\frac{d_{s}}{J_{r} N_{g}} w_{r}-\frac{d_{s}}{J_{g} N_{g}^{2}} w_{g}-\frac{\left(k_{s} \theta\right)}{J_{r} N_{g}}$

$\hat{\dot{\theta}}=w_{r}-\frac{1}{N_{g}} w_{g}$

$\ddot{z}=\frac{1}{m_{t}}\left(-K_{t} z-D_{t} \dot{z}+F_{t}\right)$

Based on the above equations, the state matrix in dimensions, $A_{e q}=[6 \times 7]$ can now be set up by differentiating all the Equations 60, 61 and 62 concerning the states.

$A_{e q}=\left[\begin{array}{ccc}\frac{-1}{\tau_{\beta}} & \cdots & 0 \\ \vdots & \ddots & \vdots \\ 0 & \cdots & \frac{D_{t}}{m_{t}}\end{array}\right]$

The input matrix dimensions, $B_{e q}=[7 \times 3]$ is found by differentiation concerning the inputs.

$B_{e q}=\left[\begin{array}{ccc}0 & \cdots & 0 \\ \vdots & \ddots & \vdots \\ 0 & \cdots & 0\end{array}\right]$

The overall state-space model with dimensions, $C_{e q}=[4 \times 5]$ is as follow.

$C_{e q}=\left[\begin{array}{ccc}0 & \cdots & 0 \\ \vdots & \ddots & \vdots \\ 0 & \cdots & 1\end{array}\right]$
The following function now gives the output power (Equation 63).

$P=\frac{\widehat{T}_{g} w_{g}}{\tau_{g}}$

A complete linearized design model has now been made over the wind turbine.

\section{Results}

A fixable, variable speed, torque, and pitch blade angle with power rating $3.5 \mathrm{MW}$ is considered in the simulation tests. To verify that the linear model behaves following the non-linear model is now compared under step wind speed. The verification consists of step response to input response of wind, pitch angle and torque. It is selected only to show the response to the three outputs $w_{r}, \mathrm{P}$ and $\theta$. The wind turbine is in the plots that linearized around a wind speed of $(14 \mathrm{~m} / \mathrm{s}-16 \mathrm{~m} / \mathrm{s})$. The amplitude of the steps is response $v_{r}=2 \mathrm{~m} / \mathrm{s}, \beta=1$ degree and $T_{g}=100 \mathrm{~N}$. Steps on the wind speed with amplitude $2 \mathrm{~m} / \mathrm{s}$ at a time of $200 \mathrm{sec}$ have been tested. The verification is for $14 \mathrm{~m}=\mathrm{s}$ with a step in the wind shown in the Figure 7. Table 1 contains all turbine specifications.

Table 1 Contains the specifications of the turbine

\begin{tabular}{lll}
\hline No. & Turbine parameter & Value \\
\hline 1 & Rotor radius & $40 \mathrm{~m}$ \\
2 & Air density & $1.225 \mathrm{~kg} / \mathrm{m}^{3}$ \\
3 & Rated rotor speed & $2.1428 \mathrm{rad} / \mathrm{s}$ \\
4 & Rated generator torque & $8376.6 \mathrm{Nm}$ \\
5 & Rotor inertia & $2.96 \times 10^{6} \mathrm{kgm}^{2}$ \\
6 & Generator inertia & $53 \mathrm{kgm}^{2}$ \\
7 & Total moment of inertia & $9.78375 \times 10^{6} \mathrm{kgm}^{2}$ \\
8 & Drive-train spring factor & $5.6 \times 10^{9} \mathrm{~N} / \mathrm{m}$ \\
9 & Drive-train damping & $10^{7} 1 / \mathrm{s}$ \\
10 & Mass of the tower & $250 \times 10^{3} \mathrm{~kg}$ \\
11 & Stiffness of the tower & $8.88 \times 10^{5} \mathrm{Nm}$ \\
12 & Damping of the tower & $296 \times 10^{2} \mathrm{Ns} / \mathrm{m}$ \\
13 & Gearbox ratio & 85 \\
14 & Pitch actuator constant & $0.12 \mathrm{~s}$ \\
15 & Generator torque constant & $0.1 \mathrm{~s}$ \\
16 & Pitch angle limit & $0^{\circ}-90^{\circ}$ \\
17 & Pitch rate limit & $\pm 10^{\circ} / \mathrm{s}$ \\
18 & Power output & $3.5 \mathrm{MW}$ \\
\hline
\end{tabular}




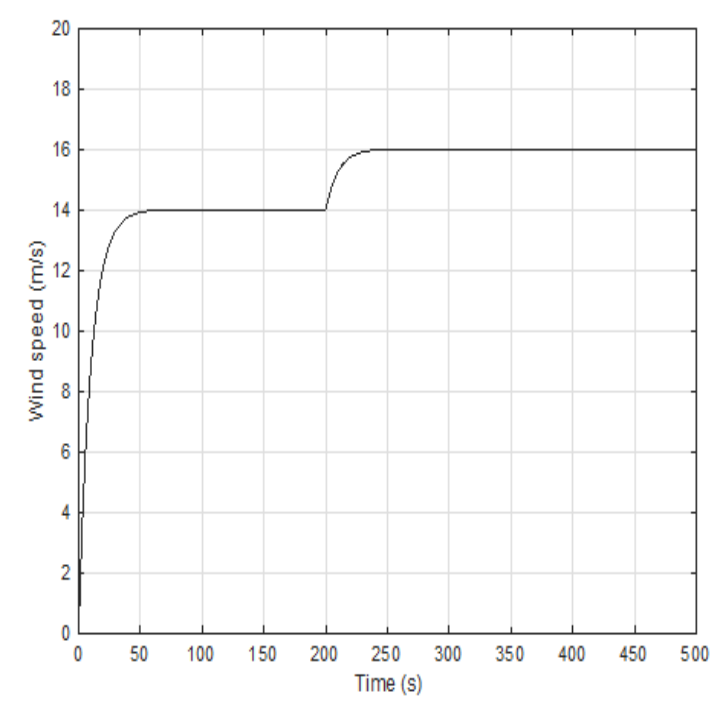

Figure 7 Step wind speed test

\section{Discussion}

The result of these simulations can be seen in Figures $(8,9,10$ and 11$)$. It can be seen from the plots that there is a good compromise between the linearized and the nonlinear turbine model. This consistency will, of course, be reduced if the step size is increased, as one will move further away from the linearized area. At a step on pitch angle, when the model is linearized around $14 \mathrm{~m} / \mathrm{s}$, linearization gives a step in the opposite direction of the other two stages. That is, accounting for the wind speed improves the model accuracy in terms of the rotor angular speed and generator angular speed. This is because the dynamics of the rotor angular speed and generator angular speed are based on the rotor torque and rotor thrust, respectively, which in turn depend on the wind speed.

The challenges of this research, there is poor agreement between the nonlinear and the calculated linear model. This is because a linearization in this area takes place at the top of the $C_{p}$ curve. However, it is so convenient that the controller in this area maximises the power output. This article analysis the linearized model of the wind turbine, also the tower structure and the turbulence effects on wind turbine efficiency. Although the nonlinear wind turbine model is accurate, it is too complicated for controller design utilization.
Linearizing the model in the state-space form representation is essential for modern controller design. A linearized model is crucial for the realtime implementation of controller design because the accurate response of the model needs to be complex computations for optimizing the control action.

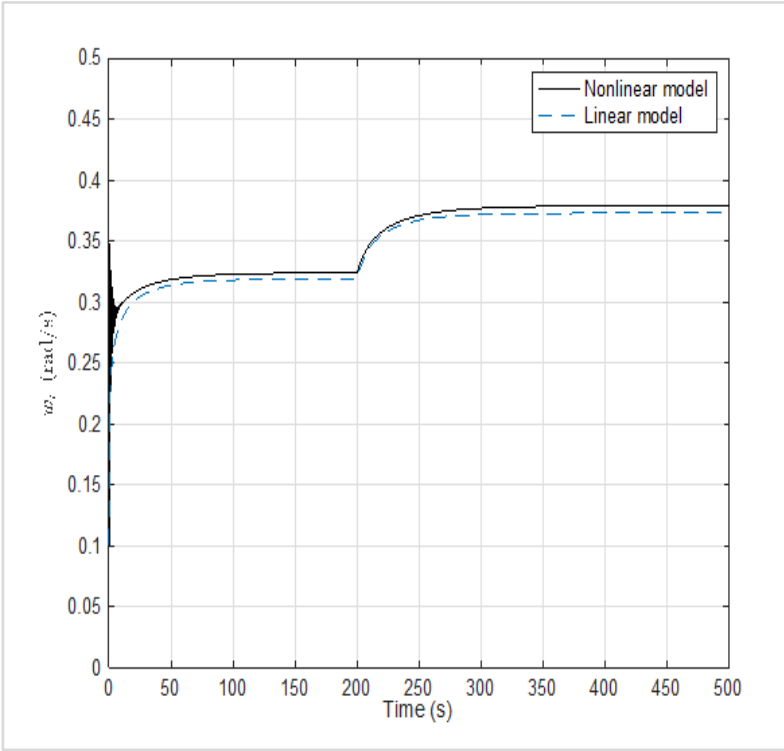

Figure 8 Angular rotor speed

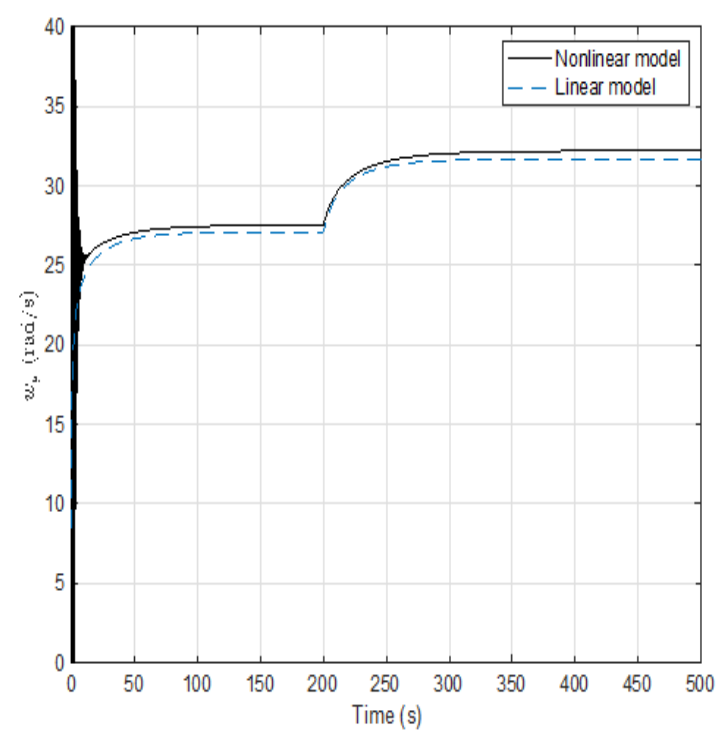

Figure 9 Angular generator speed 


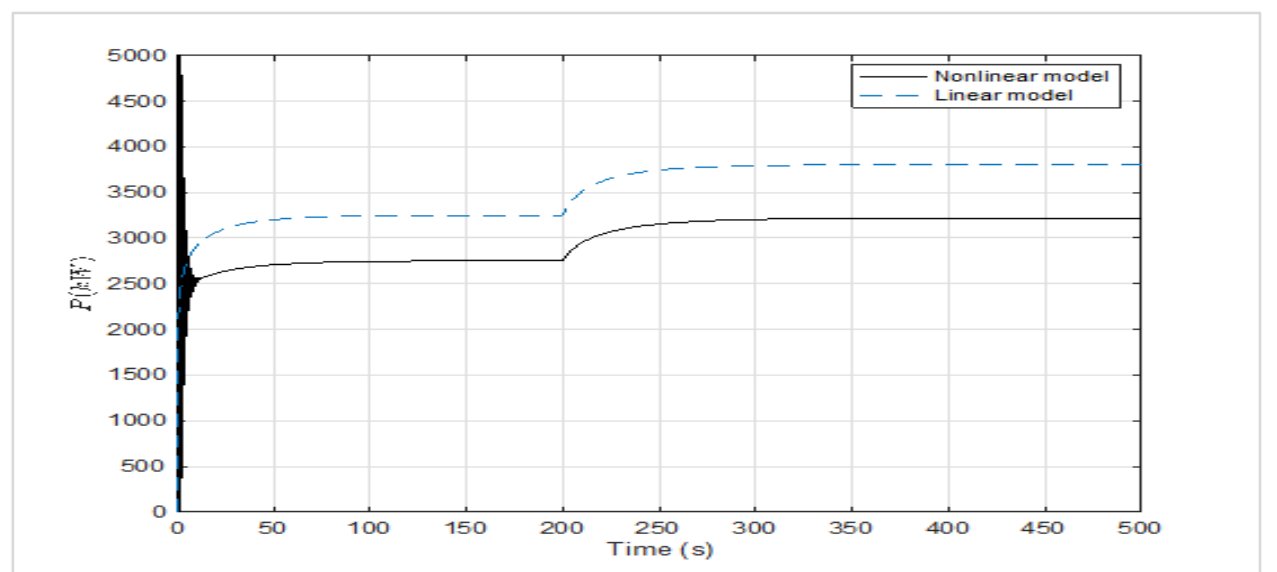

Figure 10 The output power

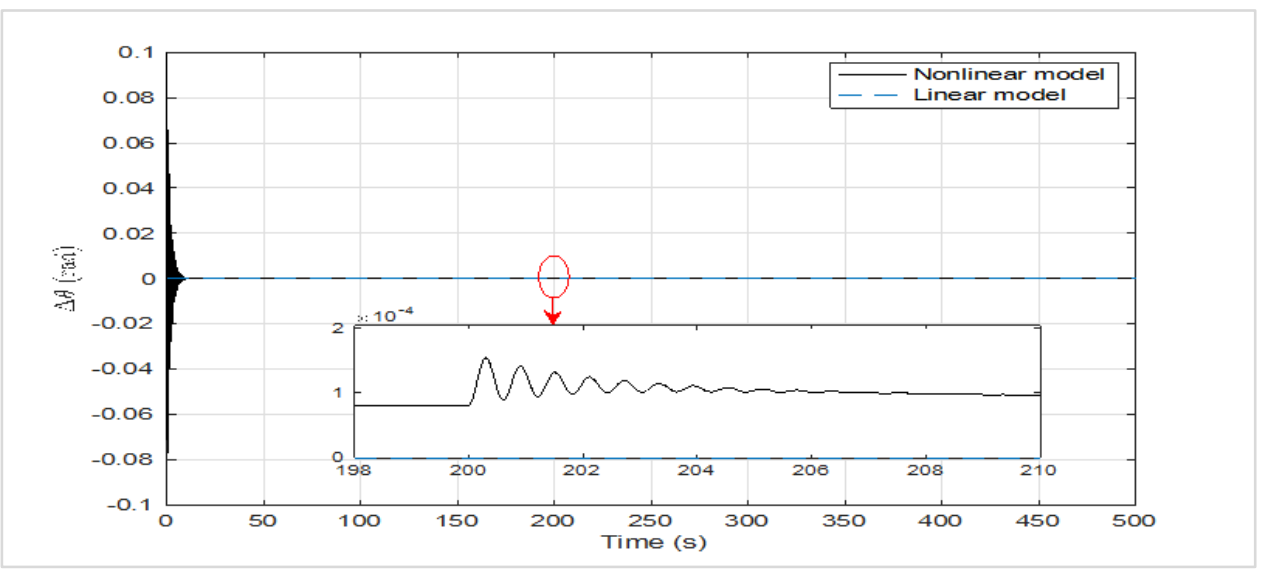

Figure 11 The linear and nonlinear model response system

\section{Conclusion and future work}

Wind turbine models will continue to evolve in more analysis methods to understand the physical mechanisms better. The state-space representations that were obtained are suitable for use in control design strategies. Many factors are considered before starting to model the wind turbine system. Therefore, a small error in the linearization could give rise to a significant deviation from the nonlinear model. This linearization, of course, is very unfortunate if a controller is to be designed. The controller will be designed to maintain the rotor speed at the rated rotation under wind flotations. We will design linear and nonlinear controllers to discuss the control strategy in more detail in future work. Future work includes modelling and control of wind turbine in more complicated situations, such as a wind shear and tower shadow disturbances.

\section{Acknowledgment}

The author would like to thank the University of Information Technology and Communications, Iraq, for financial support. The author is also grateful to the Lulea University of Technology in Sweden for accepting as a guest researcher.

\section{Conflicts of interest}

The authors have no conflicts of interest to declare.

\section{Authors contribution statement}

Thaker Nayl: Collecting data, conceptualization, investigation, data curation, writing-original draft, writingreview and editing. Mohammed Qassim: Analysis and interpretation of results. Saif Qassim: Investigation and draft manuscript preparation.

\section{References}

[1] Schmitz S. Aerodynamics of wind turbines: a physical basis for analysis and design. John wiley \& sons; 2020.

[2] Mardoude Y, Hilali A, Rahali A. Modeling and control of a wind power system based on doubly fed induction machine by aerodynamic power coefficient neural network approximation. In international conference on digital age $\&$ technological advances for sustainable development 2021 (pp. 188-92). IEEE. 
[3] Beniss MA, El MH, Lamhamdi T, El MH. Performance analysis and enhancement of direct power control of DFIG based wind system. International Journal of Power Electronics and Drive Systems. 2021; 12(2):1034-44.

[4] Hur SH. Modelling and control of a wind turbine and farm. Energy. 2018; 156:360-70.

[5] Abro KA. Numerical study and chaotic oscillations for aerodynamic model of wind turbine via fractal and fractional differential operators. Numerical Methods for Partial Differential Equations. 2020.

[6] Ahmad RT, Abdul-hussain MA. Modeling and simulation of wind turbine generator using matlabsimulink. Journal of Al Rafidain University College. 2017:282-99.

[7] Fandi G, Igbinovia FO, Ahmad I, Svec J, Muller Z. Modeling and simulation of a gearless variable speed wind turbine system with PMSG. In PES powerafrica 2017 (pp. 59-64). IEEE.

[8] Wei L, Liu Z, Zhao Y, Wang G, Tao Y. Modeling and control of a $600 \mathrm{~kW}$ closed hydraulic wind turbine with an energy storage system. Applied Sciences. 2018; 8(8):1-18.

[9] Ammar A. Performance improvement of direct torque control for induction motor drive via fuzzy logicfeedback linearization: simulation and experimental assessment. COMPEL-The International Journal for Computation and Mathematics in Electrical and Electronic Engineering. 2019; 38(2): 672-92.

[10] Pliego MA, García MFP. Advanced analytics for detection and diagnosis of false alarms and faults: a real case study. Wind Energy. 2019; 22(11):1622-35.

[11] Porté-agel F, Bastankhah M, Shamsoddin S. Windturbine and wind-farm flows: a review. BoundaryLayer Meteorology. 2020; 174(1):1-59.

[12] Hafiz F, Abdennour A. Optimal use of kinetic energy for the inertial support from variable speed wind turbines. Renewable Energy. 2015; 80:629-43.

[13] Stetco A, Dinmohammadi F, Zhao X, Robu V, Flynn $\mathrm{D}$, Barnes $\mathrm{M}$, et al. Machine learning methods for wind turbine condition monitoring: a review. Renewable Energy. 2019; 133:620-35.

[14] He X, Geng H, Mu G. Modeling of wind turbine generators for power system stability studies: a review. Renewable and Sustainable Energy Reviews. 2021.

[15] Yuvaraja T, Ramya K. Analysis of wind turbine modelling using TSMC techniques. COMPEL-The International Journal for Computation and Mathematics in Electrical and Electronic Engineering. 2018; 37(6):1981-92.

[16] Modukpe G, Diei D. Modeling and simulation of a 10 KW wind energy in the coastal area of southern Nigeria: case of ogoja. Wind Solar Hybrid Renewable Energy System. 2020.
[17] Karthik R, Hari AS, Kumar YP, Pradeep DJ. Modelling and control design for variable speed wind turbine energy system. In international conference on artificial intelligence and signal processing 2020 (pp. 1-6). IEEE.

[18] Sedaghatizadeh N, Arjomandi M, Kelso R, Cazzolato $\mathrm{B}$, Ghayesh MH. Modelling of wind turbine wake using large eddy simulation. Renewable Energy. 2018; 115:1166-76.

[19] Sun H, Qiu C, Lu L, Gao X, Chen J, Yang H. Wind turbine power modelling and optimization using artificial neural network with wind field experimental data. Applied Energy. 2020.

[20] Golnary F, Moradi H. Dynamic modelling and design of various robust sliding mode controls for the wind turbine with estimation of wind speed. Applied Mathematical Modelling. 2019; 65:566-85.

[21] Mokhtari Y, Rekioua D. High performance of maximum power point tracking using ant colony algorithm in wind turbine. Renewable Energy. 2018; 126:1055-63.

[22] Pao LY, Johnson KE. Control of wind turbines. IEEE Control Systems Magazine. 2011; 31(2):44-62.

[23] Ren H, Hou B, Zhou G, Shen L, Wei C, Li Q. Variable pitch active disturbance rejection control of wind turbines based on BP neural network PID. IEEE Access. 2020; 8:71782-97.

[24] Bianchi FD, De BH, Mantz RJ. Wind turbine control systems: principles, modelling and gain scheduling design. London: Springer; 2007.

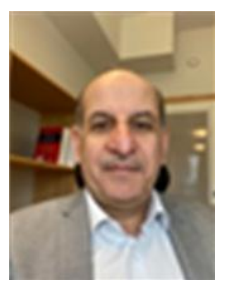

Thaker Nayl has a PhD degree in Automatic Control from the Division of Signals and Systems, Department of Computer, Electrical and Space Engineering, Luleå University of Technology, Sweden, in 2015. The research activities focus on Modelling and Control of Dynamic Systems, Articulated Vehicles and Wind Turbines. Thaker is currently working as a guest researcher at the Luleå University of Technology.

Email: thaker.nayl@uoitc.edu.iq

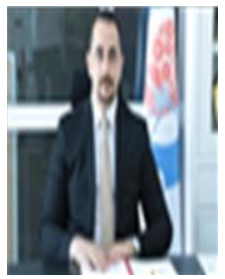

Mohammed Q. Mohammed has a $\mathrm{PhD}$ degree in Computer science from the Division of Information Technology, Department of Information Technology, Kharkiv University National of Radio electronics in 2011. The research activities focus on Modelling and Control of Dynamic Systems and Wind Turbines. Mohammed is currently working as Head of Medical Instrumental department at the Al-Esraa University college Email: dr.mohammed@esraa.edu.iq 
International Journal of Advanced Technology and Engineering Exploration, Vol 9(86)

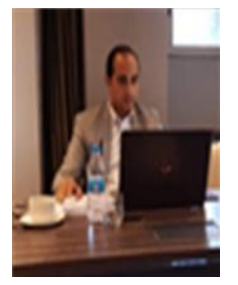

Saif Q. Muhamed has a PhD degree in Computer science from the Division of Information Technology, Department of Information Technology, Kharkiv University National of Radio electronics in 2014. The research activities focus on Modelling and Control of Dynamic Systems and Wind Turbines. Mohammed is currently working as Lecturer at University of Information Technology and Communications.

Email: dr.saif@uoitc.edu.iq 